\title{
Examining the Transformation Products of Austenite in Steels Using Backscatter Electron Imaging in the SEM
}

James H. Steele Jr.

Consultant, 2019 Nova Road, Pine CO 80470

The transformation of austenite (high temperature fcc $\boldsymbol{\gamma}$-phase) in steel has been studied since Sorby's classic optical micrographs showed the lamellar eutectoid mixture, called pearlite[1] after the color (mother of pearl). A variety of transformation products can be obtained with different alloys, and by various cooling methods. These include ferrite (low temperature bec $\boldsymbol{\alpha}$-phase) and pearlite mixtures; several bainitic microstructures[2]; and a number of variants of martensite.[3] Several different microstructural constituents in steels are shown in this paper via backscatter electron(BSE) imaging on electropolished samples. This method of final polishing allows the contrast mechanisms that control BSE signal from within the specimen to control image contrast.

Figure 1 shows a BSE image of an SAE1008 steel billet that was air-cooled following hot rolling. Proeuctectoid ferrite grains are differentiated by channeling or orientation contrast, and the pearlite is resolved by atomic number contrast between the ferrite and cementite $\left(\mathrm{Fe}_{3} \mathrm{C}\right)$ layers therein. Figure 2 provides a higher magnification image of pearlite colonies that formed within an austenite region, which had not transformed to ferrite. A cementite layer (marked with arrow) can be observed on some ferrite grain boundaries, and subgrains can also be seen within the grain at the lower right.

Figure 3 shows a BSE image of granular bainite in an AMB16 steel $(0.31 \mathrm{C} / 1.75 \mathrm{Mn} / 0.03 \mathrm{Cu} / 0.3 \mathrm{Mo}$ $/ 0.1 \mathrm{Si}$ ) that was formed by isothermal transformation in a lead bath at $370^{\circ} \mathrm{C}$. Some orientation contrast can be observed between regions that were transformed from different austenite grains. The dark thin layers are cementite that precipitated during the transformation.

Figure 4 illustrates the microstructure of a lath martensite in the same AMB16 steel that was formed by quenching in ice brine after an isothermal hold for 30 seconds at $650^{\circ} \mathrm{C}$. A thin layer of proeutectoid ferrite can be observed to have formed at a prior austenite grain boundary. The lath structure of the martensite that formed in this alloy can be observed in this micrograph.

Figure's 5 and 6 show the martensitic structure in an alloy steel $(5 \mathrm{Cr} / 5 \mathrm{Ni} / 5 \mathrm{Si} / 10 \mathrm{Mn} / 0.2 \mathrm{C})$ that was quenched in ice brine from an austenitizing temperature of $875 \mathrm{oC}$. The microstructure consists of thin sheets, which are inclined to propagate across the austenite grains, and laths that tend to fill the regions between the sheets. This type of martensitic structure is called "sheet" martensite.[2]

\section{References}

[1] G.E. Pellissier, et al., Trans. Am. Soc. Metals, 30(1942) 1049.

[2] R.F. Hehemann, Metals Handbook Vol. 8, $8^{\text {th }}$ Edition, ASM 1973, p. 194.

[3] G. Krauss and A.R. Marder, Met. Trans. 2(1971) 2343. 

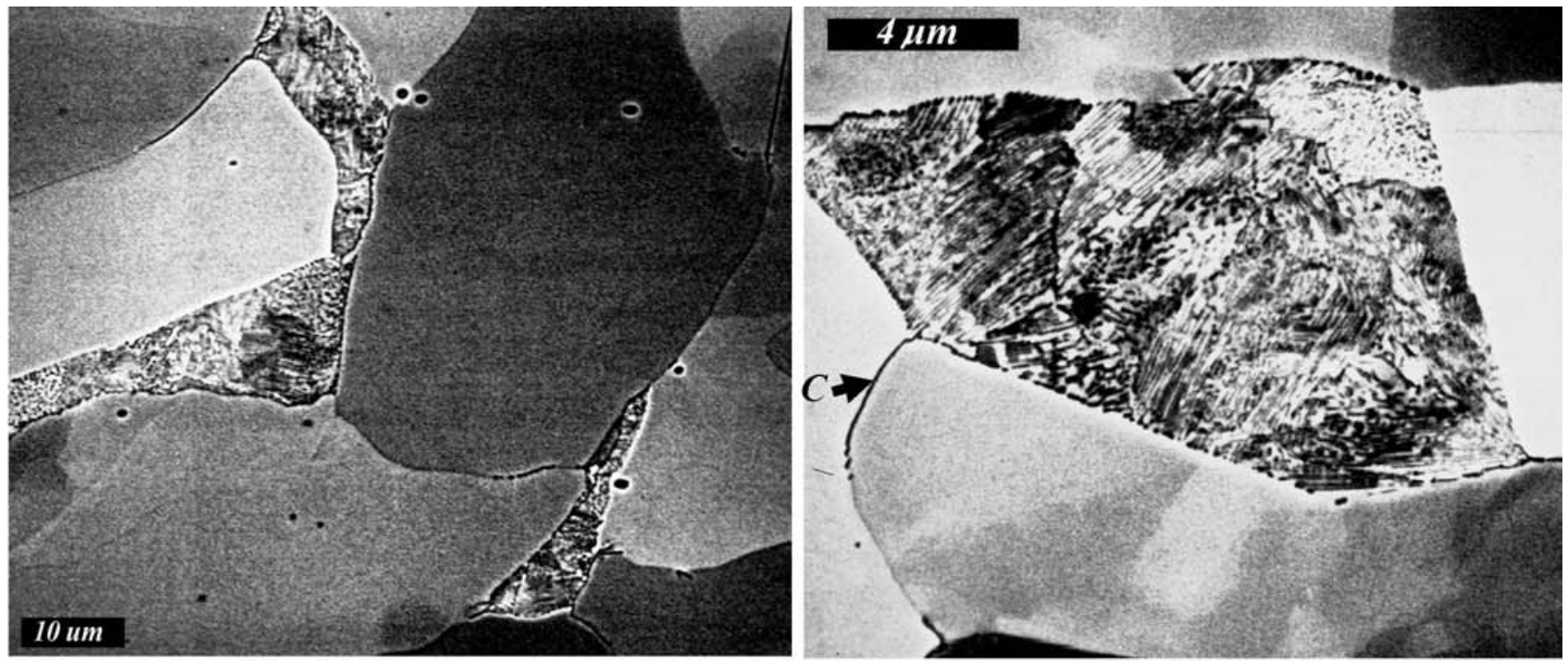

Fig. 1. Ferrite / Pearlite Microstructure in SAE1008

Fig. 2. Pearlite Colonies in SAE1008
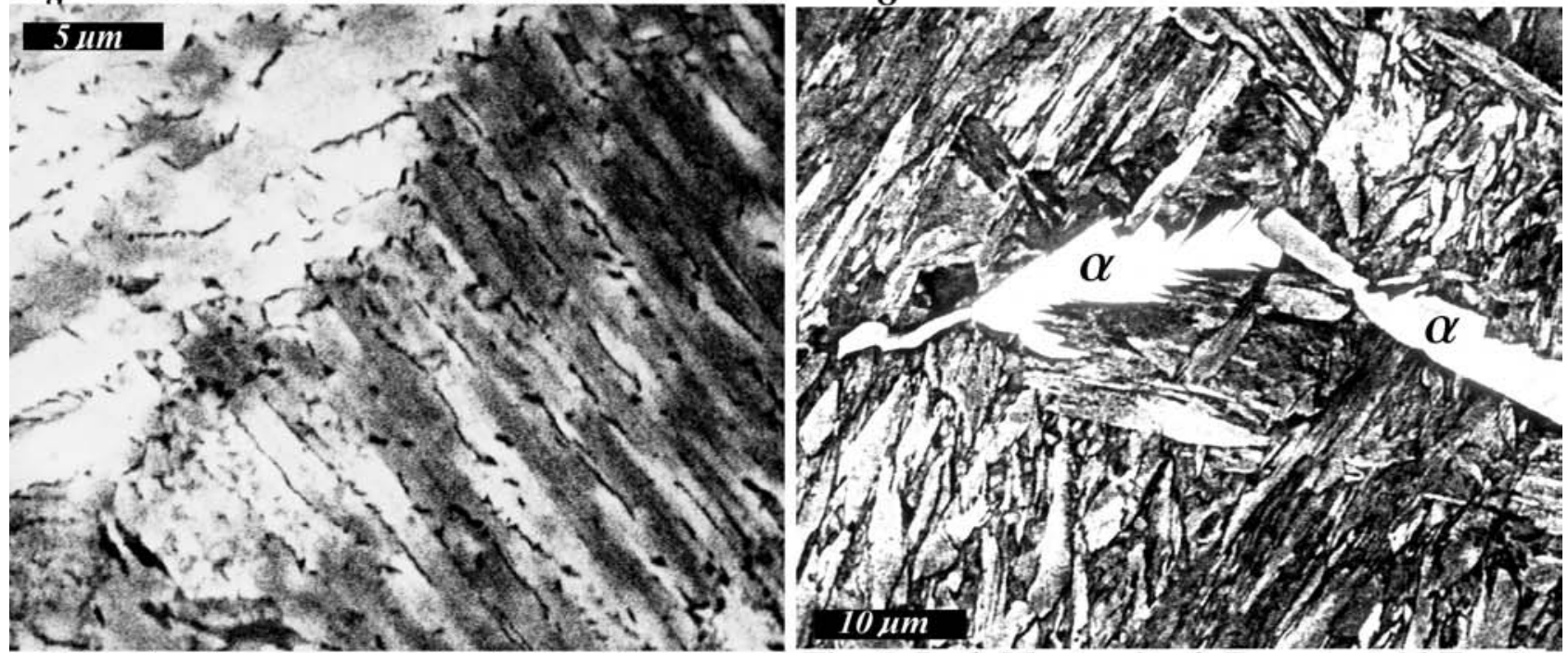

Fig. 3. Granular Bainite in AMB16.

Fig. 4. Lath Martensite \& Proeutectoid Ferrite
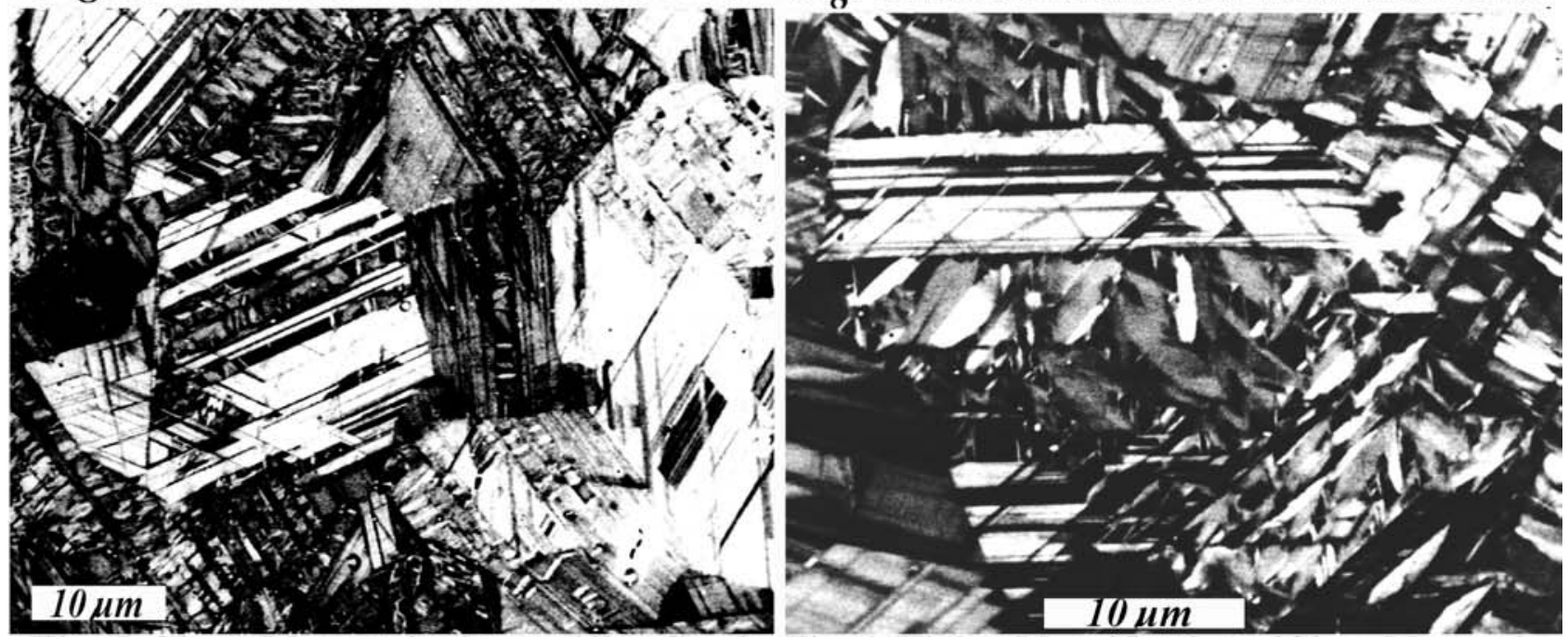

Fig. 5 Sheet Martensite in an Alloy Steel. Fig. 6 Higher Magnification of Sheet Martensite. 